\title{
Intensidade dos Processos Antropogênicos no Entorno do Reservatório do Ribeirão João Leite - Goiás - Brasil
}

\author{
Intensity of the Anthropogenic Processes \\ Around the Ribeirão João Leite Reservoir - Goiás - Brazil
}

\section{Sara Alves dos Santos ${ }^{1}$, Fabrizia Gioppo Nunes², Alex Mota dos Santos ${ }^{3}$}

1 Universidade Federal de Goiás, saraalves.amb@gmail.com

2 Universidade Federal de Goiás, fabrizia.iesa.ufg@gmail.com

3 Universidade Federal de Goiás, alex.geotecnologias@gmail.com
Recebido (Received): 29/01/2018

Aceito (Accepted): 29/08/2018

\begin{abstract}
Resumo: O reservatório do Ribeirão João Leite ocupa parte das áreas dos municípios de Goiânia, Nerópolis, Goianápolis e Teresópolis de Goiás. Seu objetivo é o abastecimento público de Goiânia e de grande parcela dos municípios de sua região metropolitana (RMG), suficiente até o ano de 2025. Apesar de sua importância, o reservatório vem sofrendo diversas pressões de interesses de múltiplos usos em seu entorno, o que poderá comprometer a sua vida útil, na questão da quantidade e qualidade de água para o abastecimento público. Neste sentido, o presente artigo visa mapear e identificar as atividades de uso e cobertura da terra no entorno do reservatório do Ribeirão João Leite, na perspectiva de avaliar o seu nível de pressão antrópica. Para tanto, fezse uso de técnicas de Processamento Digital de Imagem (PDI) e modelagem de dados em SIG. Os resultados revelam que apesar da presença de unidades de conservação, como o Parque Ecológico Altamiro Moura Pacheco e o Parque Estatual do João Leite, auxiliarem na contenção das pressões no entorno do reservatório, $42,20 \%$ de sua área apresenta atividades consideradas degradantes. Constatou-se ainda a presença de um depósito de lixo a céu aberto próximo ao reservatório. Além disso, as condições dos cursos hídricos que o abastecem são preocupantes, com nascentes já comprometidas em situações conflitantes nas Áreas de Preservação Permanente (APP).
\end{abstract}

Palavras-Chave: Pressão antrópica; Uso da terra; Mapeamento; Abastecimento de Água.

\begin{abstract}
The Ribeirão João Leite reservoir occupies part of municipalities of Goiânia, Nerópolis, Goianápolis and Teresópolis de Goiás areas. Its objective is the public water supply of Goiannia and large portion of your metropolitan region municipalities (MRM), foreseen until the year of 2025. Although your importance, the reservoir suffers several pressures of interests of multiple uses in your surroundings, which can compromise your life, on question of the quality and quantity of water for public supply. In this sense, the present article aims to map and identify the activities of land use and cover around the Ribeirão João Leite reservoir, from the perspective of evaluating your level of anthropic pressure. For such was made use of Digital Image Processing (IDP) techniques and GIS modeling. The results show that despite the presence of protected areas, like the Ecological Park Altamiro Moura Pacheco and State Park of João Leite, assist in containing the pressures surrounding the reservoir, 42,20\% of your area presents considered degrading activities. Counting with the presence of an open air garbage deposit near him. Besides that, the conditions of the water courses that supply the reservoir are concerned too, with water sources already committed and conflicting situations in Permanent Preservation Areas (PPA).
\end{abstract}

Keywords: Anthropic Pressure; Land Use and Cover; Mapping; Water Supply. 


\section{Introdução}

A intensificação e diversidade da utilização da água, refletida nos mais variados tipos de uso e ocupação da terra, tem agravado a falta de disponibilidade hídrica de qualidade para o consumo em diversas regiões do planeta. Segundo Medeiros Filho (2009), na década de 1950 a demanda de água por pessoa no planeta era de $400 \mathrm{~m}^{3}$ /ano, e atualmente, verifica-se que essa demanda dobrou. Em alguns países, como é o caso do Brasil, o aumento do consumo já revela problemas no abastecimento. Para o referido autor (2009), esta situação tenderá a ficar ainda pior, caso o consumo continue no ritmo atual.

Neste sentido, diversos são os estudos que revelam que as formas de uso da terra e a qualidade/quantidade da água, possuem relações intrínsecas, ou seja, os padrões de ocupação da paisagem influenciam tanto nas propriedades bióticas quanto abióticas das águas, configurando cenários de indicadores do estado dos ecossistemas aquáticos (GERGEL et al., 2002; HOULAHAN e FINDLAY, 2004). Destarte, para Burak e Margat (2016) são necessárias a aplicação de mecanismos capazes de mensurar e comparar o estado de conservação das áreas de captação de água para consumo público, para que assim, seja possível propor alternativas de enfretamento de seus conflitos.

De modo a enfrentar essa realidade, organizações multilaterais de ajuda, como o Banco Mundial, o United Nations Human Settlements Programme (UN-HABITAT) e a União Européia, vêm implementando diferentes sistemas de governança e gestão urbana, para apoiar o acesso equitativo e eficiente aos serviços de abastecimento de água urbana (MORETO, 2007). No Brasil, a primeira legislação que trata da questão da água data de 1934, sendo denominada "Código de Águas". Reproduzida na Constituição Federal de 1988 e regulamentada pela Lei 9.433 de 1997, que instituiu a Política Nacional de Recursos Hídricos, cria-se o Sistema Nacional de Gerenciamento de Recursos Hídricos.

Para Naji e Lustig (2006), os principais problemas da água potável nas áreas urbanas são derivados da: crescente demanda por água potável, descargas de águas residuais, poluição das águas subterrâneas, aumento da superfície de escoamento superficial, dentre outros fatores. Deste modo, é fundamental realizar o controle da qualidade da água para o consumo humano, de acordo com o que preceptua a portaria $\mathrm{n}^{\circ} .52$ do Ministério da Saúde. Assim, é importante ressaltar, que segundo Vieira e Morais (2005, p. 1), "a garantia da qualidade da água para o consumo direto, fornecida por um sistema de abastecimento público, constitui elemento essencial das políticas de saúde pública".

Desta forma, em termos de ordenamento territorial, pode-se remeter a assertiva de Lanna (1993, p. 749), quando o autor aponta que o uso dos recursos ambientais raramente ocorre de forma isolada, devendo ter a gestão dos recursos hídricos repercussão na gestão do uso do solo, e vice-versa. Cientes disto, muitos países têm regulado o uso da terra no entorno de lagos, rios e zonas úmidas, formando as chamadas zonas-tampão, também conhecidas como zonas de amortecimento (HOULAHAN e FINDLAY, 2004).

A área de amortecimento deve amortecer/diminuir os impactos de atividades exteriores à área a ser protegida. É quase que uma zona de transição entre uma de uso mais restrito e outra de ampla utilização. No caso do Brasil são utilizadas também as Áreas de Preservação Permanente (APP) para proteção do entorno dos cursos d'água, regulamentadas pelo Código Florestal Brasileiro, Lei n ${ }^{\circ} 12.651$, de 25 de maio de 2012. Uma APP tem, diferentemente da área de amortecimento, a função direta de preservar os cursos hídricos. Diz respeito a uma área cujo uso é restrito e com extensões de 30 a 100 metros do entorno dos cursos dos rios, variando de acordo com a largura de sua calha. A mesma lei prevê um raio de 50 metros ao redor das áreas de nascentes (BRASIL, 2012).

De forma geral, o Brasil apresenta contrastes significativos nas suas características demográficas e hidrológicas que não repercuti sobre a legislação, que é única para todo o país. Apesar da sua riqueza natural, amplamente divulgada pelo mundo, problemas de abastecimento são recorrentes em diversas partes do país. Desse modo, segundo Tundisi (2008, p. 13), "o Brasil, com 14\% da água do planeta, possui, entretanto, uma distribuição desigual do volume e disponibilidade destes recursos hídricos. Enquanto um habitante do Amazonas tem $700.000 \mathrm{~m}^{3}$ de água por ano disponíveis, um habitante da Região Metropolitana de São Paulo, tem $280 \mathrm{~m} 3$ por ano disponíveis".

No Cerrado, bioma responsável pela vazão de base de trechos de alguns dos principais rios brasileiros (OLIVEIRA et al., 2015), onde se localiza o estado de Goiás, o histórico de degradação ambiental não foi interrompido (SANTOS e KOIDE, 2016). Com menos de 50 anos de ocupação efetiva, esse bioma se destaca no cenário agrícola nacional e mundial (LIMA, 2011). Além disso, as regiões metropolitanas do Distrito Federal, onde está localizada a cidade de Brasília, capital federal, e Goiânia, capital do estado de Goiás, são as duas mais povoadas do Cerrado, totalizando mais de 6,7 milhões de habitantes. 
No estado de Goiás, foi construído o Reservatório do Ribeirão João Leite, cuja finalidade é o abastecimento público de água da cidade de Goiânia e da maioria dos municípios de sua região metropolitana, até o ano de 2025. O reservatório já sofre pressões advindas de diversas atividades em seu entorno, o que pode comprometer a qualidade/quantidade da água e, consequentemente, a vida útil a qual foi projetado. Em suas análises, Sousa (2013) já observava que o principal desafio para manutenção e funcionamento do Reservatório do Ribeirão João Leite é a conciliação entre os diferentes interesses de uso do solo e a conservação desse recurso hídrico.

Vale lembrar que uma das definições para o termo pressão é: "qualquer força que se exerce sobre algo" (DPLP, 2008-2013.). Enquanto o antrópico seria algo "relativo ao ser humano ou à sua ação; que resulta de ações humanas" (op. cit., 2008 - 2013). Logo, para Antunes (2012, p. 6 - 7) a designação de ação antrópica, ou atividades antropogênicas, consiste em qualquer atividade humana que interfere no funcionamento de um ecossistema. É, portanto, de acordo com Suhogusoff e Piliackas (2007), uma atividade que causa impacto no ambiente. A ação antrópica é composta assim pelas ações decorrentes da atividade humana, correspondendo a "pressão antrópica" à pressão que é exercida pelas atividades decorrentes do homem, em determinado meio geográfico.

Nessa perspectiva, pressão antrópica pode ser definida, resumidamente, como a força resultante da ação humana sobre o meio e seu nível de impacto. Portanto, o mapa de pressão insere-se na análise dos processos antropogênicos, que atuam de forma a impactar a qualidade das águas de uma bacia de captação. Serve à avaliação do sistema holístico da paisagem, pois, atua de modo a identificar o que poderá causar a contaminação. Isso porque "a garantia da qualidade da água para abastecimento público, destinada ao consumo humano está intimamente relacionada com a proteção da respectiva fonte de água bruta" (VIEIRA e MORAIS, 2005, p. 17).

De posse dessa informação, o presente artigo visa identificar e mapear os tipos de uso e cobertura da terra na zona de amortecimento do Reservatório do Ribeirão João Leite, com o intuito de avaliar o nível da pressão antrópica em seu entorno. Para tanto fez-se uso de técnicas de Processamento Digital de Imagem (PDI) e modelagem de dados em Sistemas de Informações Geográficas (SIG).

\section{2. Área de Estudo}

O Reservatório do Ribeirão João Leite (Figura 1), ocupa parte das áreas dos municípios de Goiânia, Nerópolis, Teresópolis de Goiás e Goianápolis. Pertencente ao estado de Goiás, possui área de $14 \mathrm{~km}^{2}$ de espelho d'água (PÁDUA e SOUZA, 2014), com aproximadamente $50 \%$, correspondente a parte interna do Parque Ecológico Altamiro Moura Pacheco (PEAMP). Protegido por lei está totalmente inserido na Área de Proteção Ambiental (APA) do João Leite e é envolvido pelo Parque Estadual do João Leite (PEJoL), criado no ano de 2014.

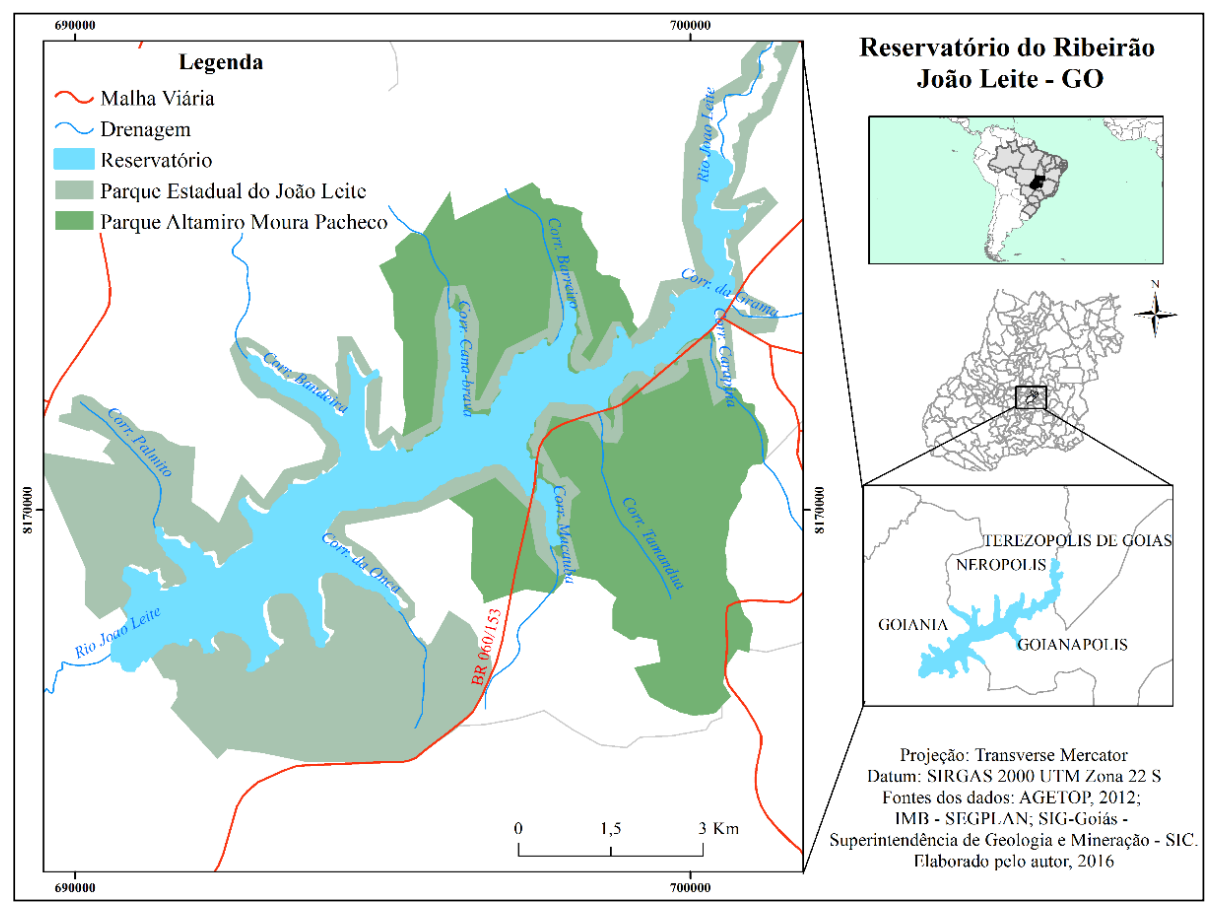

Figura 1: Localização do Reservatório do Ribeirão João Leite - GO. 
De acordo com dados disponibilizados pelo Macrozoneamento Agroecológico e Econômico do Estado de Goiás, os solos do entorno do reservatório correspondem basicamente a Latossolos, Argissolos e Cambissolos (Figura 2).

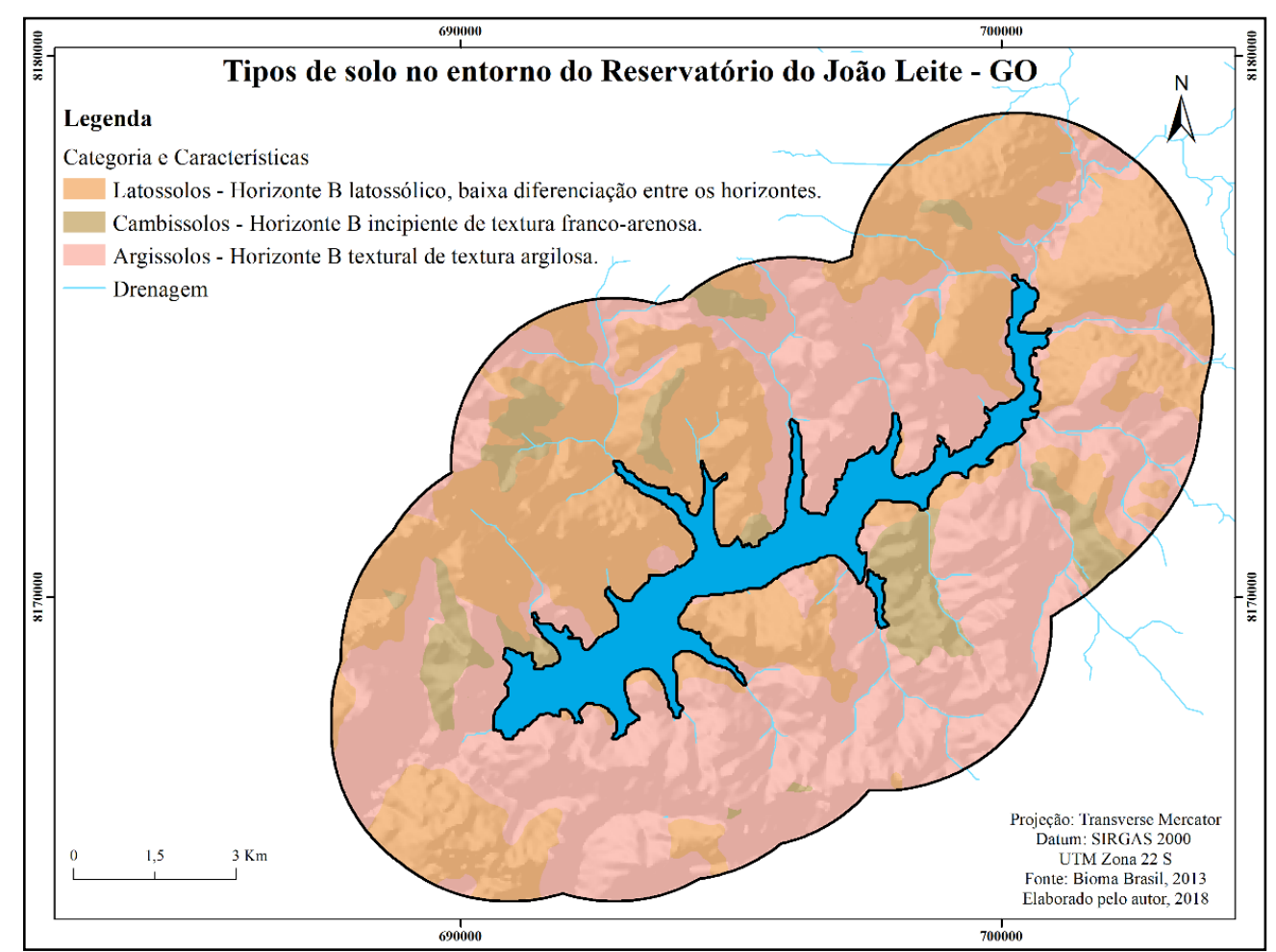

Figura 2: Solos presentes no entorno do Reservatório do Ribeirão João Leite - GO, e respectiva caracterização com base em Mendonça (2010).

De modo geral, os Latossolos são solos em avançado estágio de intemperização, muito evoluídos, como resultado de enérgicas transformações do material constitutivo. Fator, este, que contribui para maior estabilidade quando submetidos às atividades antrópicas (JACOMINE, 2008/2009).

Os Argissolos são solos que têm como uma de suas principais características o horizonto B textural, com aumento de argila do horizonte A para o B. Geralmente variam de pouco profundos a profundos (MENDONÇA, 2010). Os Cambissolos, por outro lado, são solos constituídos por material mineral, com horizonte B incipiente subjacente a qualquer tipo de horizonte superficial (JACOMINE, 2008/2009), portanto, mais susceptível a processos de degeneração de sua estrutura, quando submetido às atividades antrópicas intensivas.

A geologia, em nível da bacia, é composta por "rochas muito antigas, do período Pré-Cambriano, onde os processos erosivos esculpiram um relevo plano a suavemente ondulado, circundado por relevos mais elevados" (PÁDUA e SOUZA, 2014, p. 4). Este relevo apresenta elevações que vão de 711 a 983,7 metros, sendo que, as porções mais elevadas estão nas extremidades noroeste e sudeste da área de estudo (Figura 3). Sobre os aspectos geológicos destaca-se ainda o sistema de fraturamento no sentido NW/SE mais significativos, e sentido N/W de menor expressão. Contudo, não se sabe se existem fraturas persistentes, que indica profundidade que caracterizaria melhor se contaminantes atingem as águas subterrâneas mais rapidamente.

A caracterização desses elementos da paisagem é importante, pois são sobre eles que atuam os eventos perigosos, que expõe o sistema de captação a processos de riscos. De forma geral, esses eventos perigosos na bacia hidrográfica podem estar associados, segundo Vieira e Morais (2005), a descarga de águas residuais (domésticas e industriais), descargas de águas pluviais provenientes de rodovias, lixiviação provenientes da utilização de produtos químicos (pesticidas e fertilizantes), as atividades de recreação, matéria orgânica fecal proveniente de vida silvestre e principalmente da criação de gado, ocorrências de constituintes de rochas naturais, variações sazonais climáticas (cheias e secas) e desastres naturais.

Quanto a litologia, esta é constituída predominantemente por granada gnaisse, anfibolito e quartizito; ortognaisse e migmatito, pertencentes as unidades geológicas supracrustais, Jurubatuba e Silvânia (Figura 4). A geologia, assim como os solos, são constituintes importantes para avaliar os níveis de pressão, pois influenciam diretamente nas taxas de recarga dos aquíferos (SANTOS e KOIDE, 2016). 


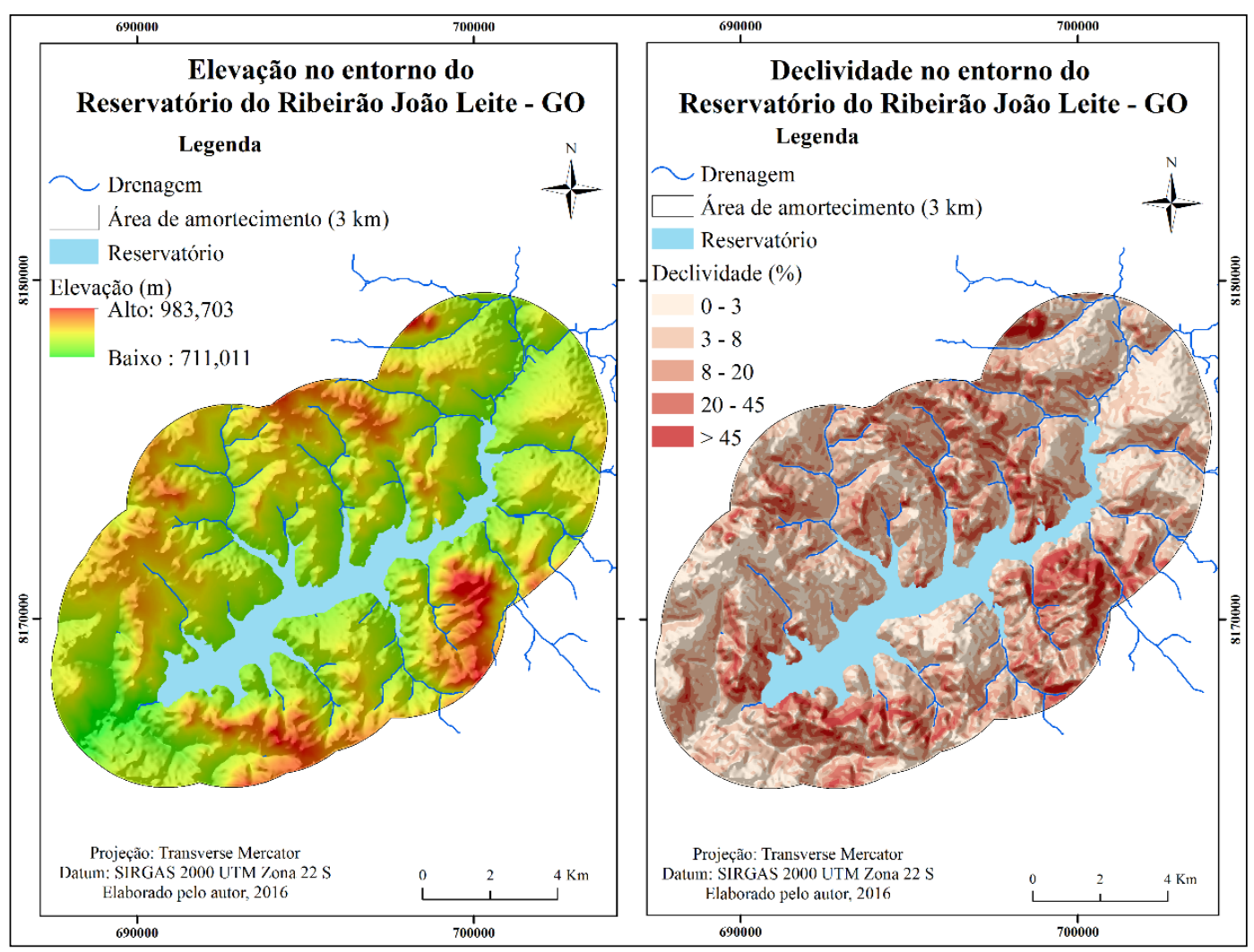

Figura 3: Elevação e declividade no entorno do Reservatório do Ribeirão João Leite - GO.

No conjunto hidrográfico, o Reservatório do Ribeirão João Leite pertence a bacia hidrográfica de mesmo nome e é afluente do rio Meia Ponte, formador do médio curso do Rio Paranaíba, ainda no estado de Goiás. O fato da maioria dos rios que drenam o território goiano serem de domínio da União faz com que, a gestão dos recursos hídricos do estado seja realizada de forma compartilhada entre o estado de Goiás e a União, caso do Rio Paranaíba e de seus afluentes. Neste sentido, mesmo possuindo o seu próprio Comitê, uma das dificuldades do Comitê da Bacia do Rio Meia Ponte é que este deve estar sempre de acordo com a lógica global do comitê da bacia federal a qual pertence.

A bacia do rio Meia Ponte é considerada como a mais populosa de Goiás, onde já é perceptível algumas irregularidades no saneamento básico de suas áreas urbanizadas. Nas áreas rurais, como principais problemáticas são observadas a erosão do solo, provocada pela falta de manejo adequado, uso indiscriminado de agrotóxicos, exploração mineral de argila, brita e areia, além da presença de indústrias que usam os mananciais como receptores de seus efluentes.

\section{Materiais e Métodos}

Para determinação da área de estudo calculou-se um raio de três quilômetros a partir da cota do reservatório. Como este não possui uma zona de amortecimento definida, utilizou-se como base a legislação para zona de amortecimento de unidades de conservação (Resolução CONAMA no $428 / 2010$ ), uma vez que o reservatório está situado em uma UC de Uso Sustentável e seus limites englobam duas áreas de Proteção Integral, além de ter como objetivo principal o abastecimento público da RMG.

A metodologia aplicada consistiu no mapeamento do uso e cobertura da terra do raio estabelecido, para a posterior aplicação do Índice de Pressão Antrópica (IPA), apresentado por Santos e Gomide (2015) e que foi derivado do Índice de Transformação Antrópica (ITA) de Lémechev (1982).

O ITA tem a finalidade de quantificar o grau de modificação da paisagem (COCCO et al., 2015), possibilitando a mensuração da pressão antrópica sobre alguns componentes da paisagem, o que permite uma avaliação do grau de antropização específico que ocorre em cada unidade ambiental da paisagem analisada (GOUVEIA et al., 2013). Esse tipo de avaliação foi utilizada por alguns autores para análise de pressão em fragmentos de florestas (LOURENÇO et al., 2015), bacias hidrográficas (GOUVEIA et al., 2013; COCCO et al., 2015), Terras Indígenas (SANTOS e GOMIDE, 2015), rodovias (ROCHA e CRUZ, 2009) e unidades de conservação. 
Para o cálculo do IPA além das informações contidas no mapa de uso e cobertura da terra foram empregados dados de focos de queimada, pivôs de irrigação, localização de lixões, solos, geologia e áreas de exploração mineral (Tabela 1), aos quais se atribuiu pesos, a serem submetidos à análise de álgebra de mapas em ambiente SIG.

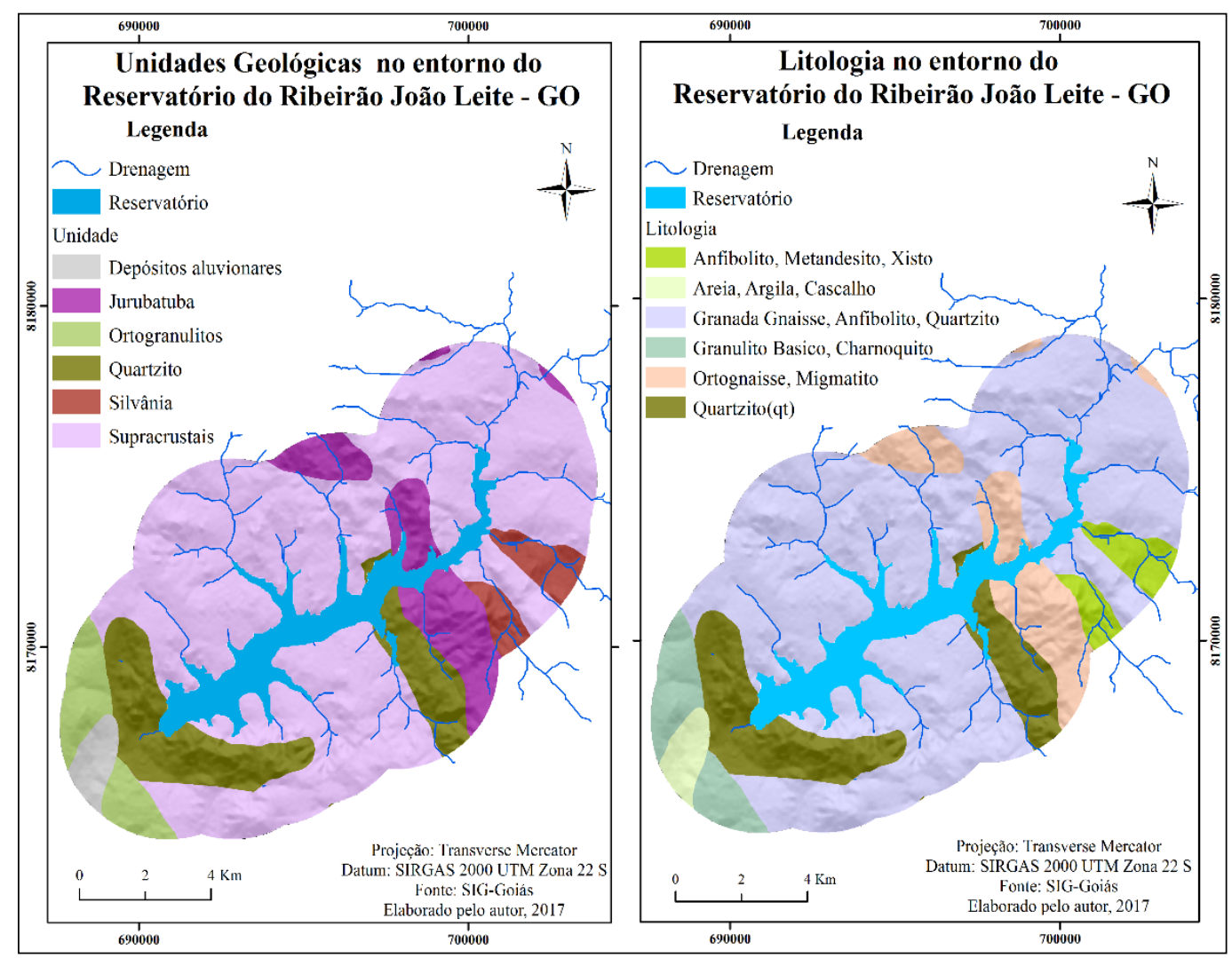

Figura 4: Geologia no entorno do Reservatório do Ribeirão João Leite - GO.

O mapa de uso e cobertura foi gerado por meio da classificação supervisionada da imagem de satélite LANDSAT 8, no Sistema de Processamento de Informação Georeferenciada (SPRING), versão 5.4.1. O método de classificação utilizado foi o Bhattacharya, por regiões, que de acordo com Oliveira e Mataveli (2013, p. 0092) "utiliza a distância Bhattacharya para medir a separabilidade estatística entre cada par de classes espectrais". Para o mapeamento, as classes de uso selecionadas foram: culturas temporárias, água, área campestre, estrada, áreas de mineração, pastagem, silvicultura, áreas urbanizadas, pivôs e área florestal, que foram nomeadas de acordo com as orientações do Manual Técnico de Uso da Terra do IBGE (2013).

Tabela 1: Tipo e fonte dos dados utilizados

\begin{tabular}{c|c|c|c|c|c}
\hline Dados & Órbita/Ponto & Data & Bandas & Projeção & Fonte \\
\hline Imagem Landsat 8 & $222 / 71$ & $11 / 08 / 2015$ & 654 & UTM SIRGAS 2000 & USGS \\
\hline MDE & $\mathrm{X}$ & $\mathrm{X}$ & $\mathrm{X}$ & UTM SIRGAS 2000 & TOPODATA \\
\hline Focos de Queimada & $\mathrm{X}$ & 2015 & $\mathrm{X}$ & UTM SIRGAS 2000 & INPE \\
\hline Lixão & $\mathrm{X}$ & $26 / 06 / 2014$ & $\mathrm{X}$ & UTM SIRGAS 2000 & SEMARH e SEAGRO \\
\hline Empreendimento Mineiro & $\mathrm{X}$ & 2008 & $\mathrm{X}$ & UTM SIRGAS 2000 & SIG-Goiás \\
\hline Pivôs de Irrigação & $\mathrm{X}$ & 2013 & $\mathrm{X}$ & UTM SIRGAS 2000 & $\begin{array}{c}\text { IMB-SEGPLAN } \\
\text { / SRH-SEMARH }\end{array}$ \\
\hline Geologia & $\mathrm{X}$ & 2009 & $\mathrm{X}$ & UTM SIRGAS 2000 & SIG-Goiás \\
\hline Solos & $\mathrm{X}$ & 2013 & $\mathrm{X}$ & UTM SIRGAS 2000 & Biomas Brasil \\
\hline
\end{tabular}

A Tabela 2 apresenta os pesos atribuídos para cada variável: classes de uso e cobertura da terra, solos e geologia. O valor dos pesos foi estimado com base na capacidade de impacto de cada um, aferida a partir: da classificação feita por Salomão (1999), para a suscetibilidade a erosão laminar dos diferentes tipos de uso e cobertura do solo; da vulnerabilidade dos solos exposta por Crepani et al. (2008), bem como, dos pesos adotados por Santos e Gomide (2015), para a aplicação do IPA. 
Tabela 2: Pesos atribuídos às classes de uso e cobertura e geologia.

\begin{tabular}{l|l|l|l}
\hline Classes de Uso & Peso & Fonte & Ano \\
\hline Área de Mineração & 10 & Mapa de uso/cobertura & 2015 \\
\hline Áreas Urbanizadas & 10 & Mapa de uso/cobertura & 2015 \\
\hline Lixão & 10 & SEMARH e SEAGRO & 2014 \\
\hline Pivô de Irrigação & 10 & IMB/ SRH & 2013 \\
\hline Culturas Temporárias & 9 & Mapa de uso/cobertura & 2015 \\
\hline Estrada & 10 & Mapa de uso/cobertura & 2015 \\
\hline Focos de Queimadas & 9 & INPE & 2015 \\
\hline Pastagem & 8 & Mapa de uso/cobertura & 2015 \\
\hline Silvicultura & 7 & Mapa de uso/cobertura & 2015 \\
\hline Área Campestre & 5 & Mapa de uso/cobertura & 2015 \\
\hline Área Florestal & 1,5 & Mapa de uso/cobertura & 2015 \\
\hline Água & 1 & Mapa de uso/cobertura & 2015 \\
\hline Solo & Peso & Fonte & Ano \\
\hline Argissolos & 5 & Bioma Brasil & 2015 \\
\hline Cambissolos & 7 & Bioma Brasil & 2015 \\
\hline Latossolos & 2,5 & Bioma Brasil & 2015 \\
\hline Litologia & Peso & Unidade Geológica & Peso \\
\hline Areia, Argila, Cascalho & 10 & Depósitos aluvionares & 8 \\
\hline Ortognaisse, Migmatito & 8 & Ortogranulitos & 8 \\
\hline Anfibolito, Metandesito, Xisto & 8 & Supracrustais & 8 \\
\hline Granulito Básico, Charnoquito & 8 & Quartzito & 8 \\
\hline Quartzito(qt) & 8 & Jurubatuba & 6 \\
\hline Granada Gnaisse, Anfibolito, & 8 & Silvânia & 6 \\
Quartzito & & & \\
\hline
\end{tabular}

Fontes: Adaptado de SALOMÃO (1999); CREPANI et al. (2008); SANTOS e GOMIDE (2015).

Com o uso do processamento de "álgebra de mapas" do ArcMap 10.1, versão para estudante, as variáveis foram aplicadas a fórmula: IPA $=\Sigma$ (classes de uso da terra*Peso + solos*Peso + geologia *Peso) /3.

Ao modelo gerado foram atribuídas classes que variam entre 1 e 5 , em que 1 corresponde a menor pressão e 5 a maior. Após esta etapa, calculou-se a área corresponde a cada classe e foram confeccionados mapas temáticos e gráficos. Realizou-se também, trabalhos de campo na área de estudo para validação das classes do mapa de uso e dos fatores de degradação identificados, além da aquisição de material fotográfico ilustrativo.

\section{Resultados e Discussão}

Nas visitas feitas in loco, foi possível identificar na zona de amortecimento do reservatório a presença de: área para dessedentação de animais, assoreamento, desmatamento, efluentes, implantação de barramentos (reservatórios, lagos, barragens, etc.), indústrias, granjas, matadouros, frigoríficos, irrigação de lavouras e hortaliças, lixão, chiqueiro, loteamentos provenientes da expansão urbana, piscicultura, ponto de banhistas e lazer, práticas agropecuárias e práticas de queimadas ocasionando a poluição e degradação do manancial.

Do mapa de uso e cobertura da terra, pode-se constatar que as formações florestais correspondem a 43,24\% da área estudada, o que reflete, em parte, o papel desempenhado pelas unidades de conservação. São esses os locais sob menor pressão antrópica, uma vez que a cobertura vegetal tem permitido a proteção do solo e dos mananciais. A proteção da vegetação sobre os recursos hídricos foi alvo de profunda revisão apresentada por Andréassian (2004). O autor refere que a proteção das coberturas vegetais pode variar em função das características climáticas e pedológicas, de cada lugar. Adicionalmente, para Tucci e Mendes (2006, p. 14), de modo geral, "a vegetação tem um papel fundamental no balanço de energia e no fluxo de volumes de água", em que se destaca a influência sobre a infiltração, retenção de água, evaporação, transpiração, escoamento superficial, dentre outros.

Em contrapartida, as áreas com atividades antrópicas consideradas degradantes do ecossistema local, chegam a $42,20 \%$, isso sem contabilizar as áreas de campo, que podem ou não estarem sendo utilizadas para o pastoreio de gado. Nesta questão, Medeiros Filho $(2009$, p. 3) lembra que "na ausência de coberturas vegetais, sobre terrenos de solos compactados, a tendência das chuvas é de escoar rapidamente pela superfície, em direção aos cursos de água, o que traz como consequência: as inundações, a aceleração do processo de erosão e diminuição da estabilidade dos cursos de água. Desta forma, o volume de um corpo hídrico, desprovido de vegetação em seu entorno, tenderá a ficar reduzido fora do período de cheias, comprometendo as atividades 
agrícolas e de pisciculturas, e no caso do Reservatório do Ribeirão João Leite, o abastecimento de água da RMG”.

Como atividades que configuram áreas significativas de agentes de pressão sobre o reservatório, pode-se destacar: as culturas temporárias (10,36\%), áreas urbanizadas $(1,95 \%)$ e de pastagens $(27,27 \%)$. As pastagens e culturas temporárias encontram-se distribuídas ao longo de toda a região estudada, intercaladas com pequenos trechos de formações campestres. Enquanto as manchas urbanas concentram-se nas extremidades nordeste e sudoeste do reservatório (Figura 5).

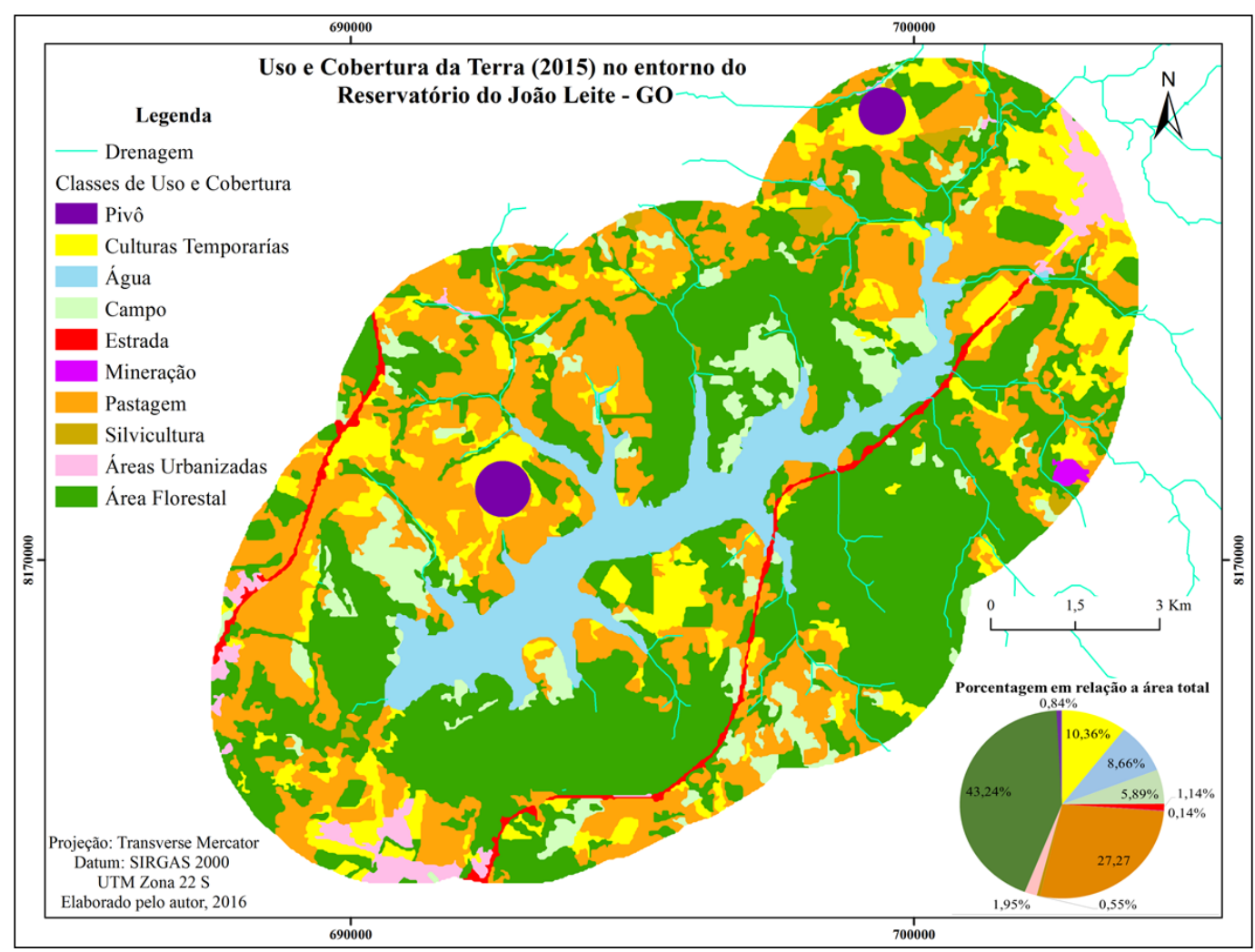

Figura 5: Uso e cobertura da terra no entorno do Reservatório do Ribeirão João Leite em 2015.

É notório que os trechos urbanos são áreas de elevada atividade antrópica, uma vez que demandam maior consumo de água e geram conflitos de uso, provenientes dos efluentes de esgotos domésticos e das áreas de depósito de lixo, que podem atingir o reservatório, principalmente derivada da mancha urbana situada a montante. Já as pastagens são áreas de atividade antrópica moderada, que podem provocar uma série de impactos como compactação e desgaste do solo, além do escoamento de matéria orgânica proveniente das fezes do gado bovino.

Da avaliação dos dados mapeados foi possível identificar também pontos de exploração de cascalhos/areia, de cerâmica e de pivôs de irrigação, às margens do reservatório, além da já citada área de lixão situada a nordeste (Figura 6). Atividades essas consideradas altamente impactantes e poluidoras. Vale ressaltar que no lixão observou-se que não há seletividade de lixo, e nem proteção aparente do solo contra a infiltração de chorume. No mesmo há presença de pássaros a sobrevoo, resíduos sem cobertura e chorume exposto. Trata-se de um aterro que já foi controlado, que recebe resíduos do município de Teresópolis-GO e ocasionalmente de outros municípios vizinhos. De acordo com Xiaoli et al. (2007), um dos principais problemas encontrados é o alto teor de metais pesados no solo e vegetação.

$\mathrm{Na}$ análise, nota-se que em 2015 há concentração de focos de queimadas na porção sudeste da área de estudo, principalmente nas proximidades do Parque Estadual João Leite (PEJoL). Mesmo sendo protegido por lei, são verificados focos de queimadas no interior de seu fragmento florestal, situado próximo à rodovia e a linha de transmissão de energia. Enquanto que no Parque Ecológico Altamiro Moura Pacheco (PEAMP), foram identificados poucos focos, apenas 3 , e em suas extremidades.

O fato de uma rodovia, a BR 060/153, cortar o reservatório também é crítico, visto que, como pontuado por Sousa et al. (2009), a construção de estradas e rodovias acarretam a fragmentação das paisagens naturais e efeito de borda, facilitam o surgimento de focos de queimadas, além do risco de contaminação da água por 
produtos transportados, em caso de acidentes ou vazamentos. Como impactos das rodovias nos cursos d'água pode-se citar ainda: a presença de solo exposto, assoreamento, restos de obra, ausência de vegetação na APP e alteração na qualidade limnológica dos cursos no indicador turbidez. Além disso, identificou Estradas Não Pavimentadas (ENPs), que segundo Bertolini et al. (1993), destaca-se a erosão como principal impacto ambiental, sobretudo na forma hídrica, sendo uma das principais formas de degradação das terras.

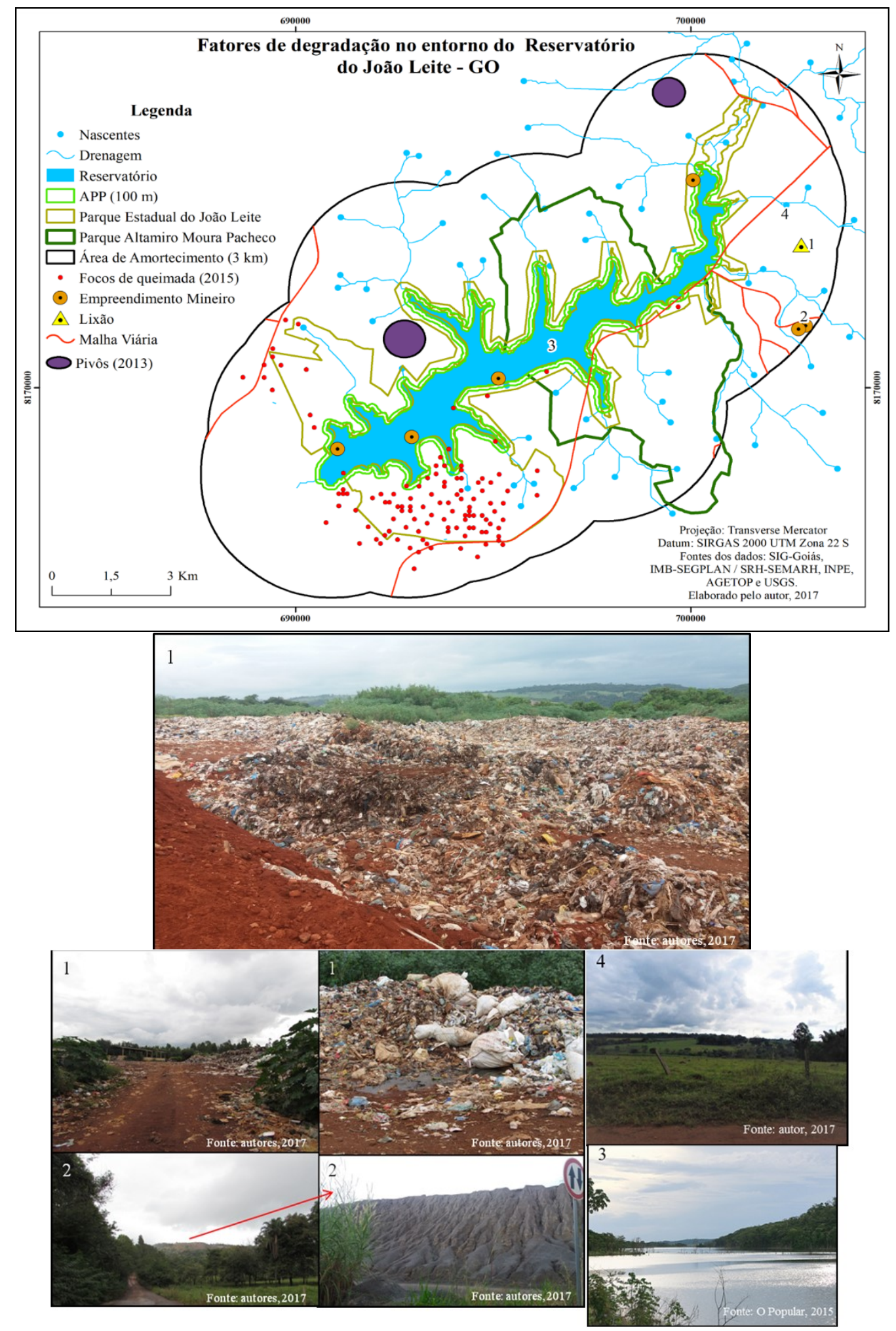

Figura 6: Fatores de degradação no entorno do Reservatório do Ribeirão João Leite. (1- lixão de Teresópolis; 2 - mineradora com exploração de areia e brita; 3 - espelho d'água do reservatório; 4 - área de pastagem). 
Quanto ao Índice de Pressão Antrópica, as classes definidas correspondem a: 1 - pressão mínima; 2 - pressão baixa; 3 - moderada; 4 - alta e; 5 - muito alta. Desta forma, os cálculos realizados demonstram que mais de $20 \%$ do entorno do reservatório apresenta elevado IPA, ou seja, uma pressão antrópica muito alta (Figura 7), enquanto que $27,48 \%$ possui nível alto. Logo, aproximadamente $50 \%$ do entorno do reservatório encontra-se sobre considerável pressão antrópica. Apesar disso, 41,25\% deste ainda apresenta IPA de baixo a moderado, o que se deve em parte a presença das UC implantadas e de outras áreas de fragmentos florestais remanescentes, ainda não eliminados pelas atividades agropastoris.

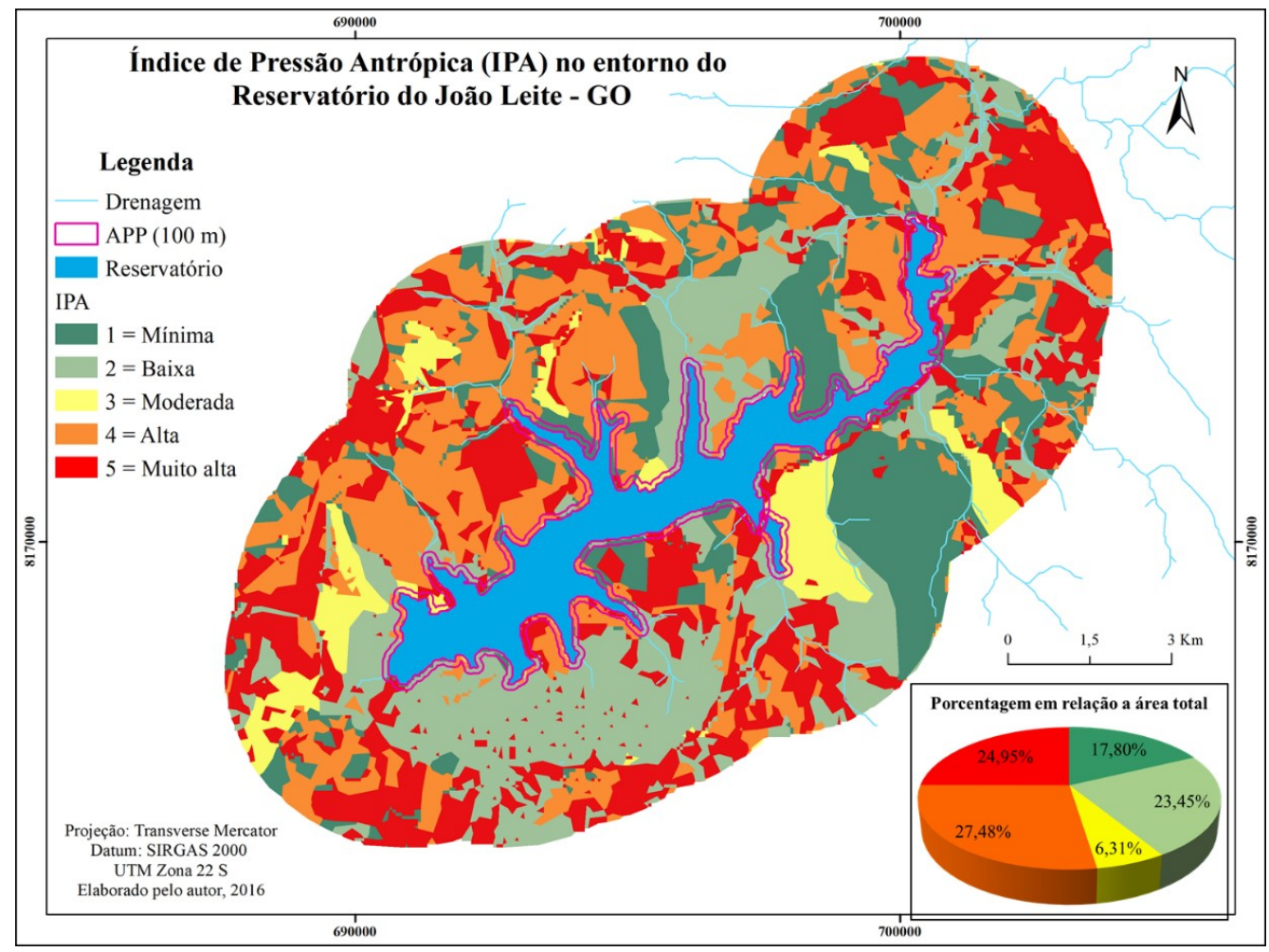

Figura 7: IPA no entorno do Reservatório do Ribeirão João Leite.

Ao se considerar uma APP de 100 m para o reservatório (a máxima proposta pelo Código Florestal), em virtude de se tratar de um reservatório destinado ao abastecimento humano e com extensão considerável, observaremos que a mesma também se encontra comprometida, com 23,9\% (149,3 ha) de sua área ocupada por pastagens, e com nível de pressão considerável, chegando a classe 5 em alguns trechos. Isso em virtude da rodovia, que corta o reservatório, e da presença de áreas de agricultura bem próximas a sua margem.

Em termos de bacia, a bacia hidrográfica do Ribeirão João Leite à qual pertence o reservatório, encontrase em estado de conservação seriamente comprometido. Em 2009 restavam apenas 12\% de Cerrado nativo ainda preservado (RABELO et al., 2009). O mesmo estudo indicou que na água do Ribeirão João Leite os parâmetros de turbidez, DBO, nitrato, resíduos totais, fosfato, nitrogênio amoniacal e coliformes fecais estavam acima do permitido, estando em melhor qualidade apenas no ponto de captação da água para a metrópole de Goiânia, devido a presença do PEAMP (Parque Estadual Altamiro Moura Pacheco).

Em 2013 pesquisadores da Universidade Federal de Goiás já alertavam para o risco ao qual a qualidade do reservatório corria devido à fatores como ausência de mata ciliar em suas margens, áreas urbanas e uso de agrotóxicos e fertilizantes em plantações próximas (NAYARA, 2013). Apesar dos riscos e problemáticas existentes, a Saneago (Saneamento de Goiás) verificou que a qualidade da água do Manancial do Ribeirão João Leite encontra-se em condições aceitáveis, de ser tratada para o consumo e abastecimento humano (SANEAGO, 2008; ABREU, 2013).

No entanto, é preocupante o fato dos cursos d'água que contribuem para alimentação do reservatório advirem de áreas com alta pressão antrópica, podendo gerar danos em cadeia, afetando-o seriamente. Algumas problemáticas já podem ser observadas, em 2015 o G1 noticiou que 23 das 491 nascentes que compõem a bacia do Ribeirão João Leite não poderiam mais ser recuperadas, colocando em risco a vida útil do reservatório. Do total de nascentes, apenas 70 estariam preservadas de maneira integral (RESENDE, 2015).

Ao analisarmos a condição das Áreas de Proteção Permanente dos cursos d'água (30m) e das nascentes $(50 \mathrm{~m})$, na zona de amortecimento do reservatório, notamos que cerca de $20 \%$ destas encontram-se em 
condição de uso indevido, convertidas em atividades como culturas temporárias e pastagens. Na Figura 8 percebe-se que são poucos os cursos que apresentam toda sua APP em boas condições de preservação, levando em conta, que $100 \%$ destas áreas deveriam estar com vegetação arbórea ou arbustiva de acordo com o previsto no Código Florestal Brasileiro.

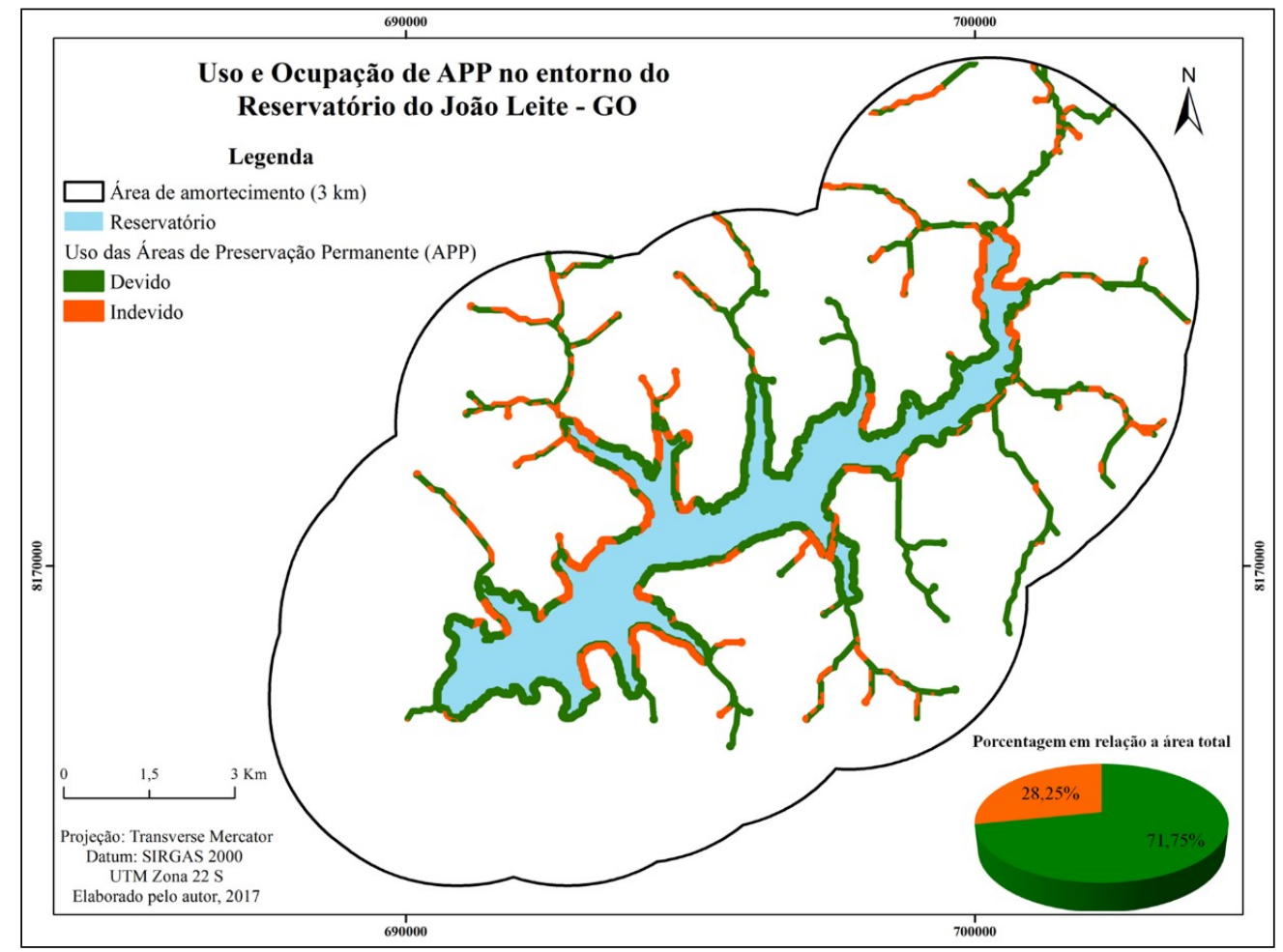

Figura 8: APP de cursos d'água e de nascentes no entorno do Reservatório do Ribeirão João Leite.

Houlahan e Findlay (2004) já alertavam, que a crença de que apenas nas proximidades adjacentes ao curso d'água os tipos de uso da terra podem afetar a sua qualidade, pode vir a ser equivocada, pois, cada ambiente possui uma realidade e escala de impacto diferente. Assim, é importante ressaltar que os formuladores de opiniões públicas e das políticas de gestão de recursos hídricos necessitam compreender a distância dos recursos hídricos em uma escala holística da paisagem, incluindo a criação de princípios e diretrizes compatíveis a cada especificidade.

\section{Considerações Finais}

Constatou-se que mais de $40 \%$ da cobertura vegetal original, da zona de amortecimento do Reservatório do Ribeirão João Leite foi convertida em algum tipo de atividade antrópica. Entre essas atividades, a classe de pastagem foi a que apresentou o maior potencial de modificação da paisagem, seguida da classe de culturas temporárias. Este fato reflete a expansão das fronteiras agropecuárias no desenvolvimento econômico do estado de Goiás, transformando-o em uma das maiores potências do país, em detrimento da proteção e conservação de seus recursos naturais.

Apesar da presença das unidades de conservação, como o Parque Ecológico Altamiro Moura Pacheco e do Parque Estatual do João Leite, auxiliarem na contenção da pressão no entorno do reservatório, o IPA ainda é alto. Este é resultado principalmente da proximidade de núcleos urbanos, atividades agropecuária, mineração, lixão e do fato do reservatório ser cortado por uma rodovia. Além disso, os cursos d'água que o compõe também estão ameaçados pela ação antrópica. Este fato é preocupante e faz com que se torne necessária a adoção de medidas mitigadoras e preventivas que minimizem novos impactos, visto que estas pressões podem vir a comprometer o abastecimento público da RMG, a longo ou até mesmo a curto prazo.

Como ferramenta de apoio, o mapeamento realizado permite a visualização geral do estado de conservação, versus nível de pressão no entorno do Reservatório do Ribeirão João Leite. Este produto pode auxiliar na formulação da gestão do uso do solo e da melhor manutenção e conservação do reservatório.

Por fim, entende-se que a zona de amortecimento a ser protegida faz parte de uma estratégia que potencializa a conservação da água, do solo e do próprio abastecimento de água da RMG. Além disso, é 
consenso que para uma boa gestão de recursos hídricos é fundamental a questão da qualidade e quantidade da água, em nível de bacia hidrográfica, que disponibilize de um comitê gestor, organizador e fiscalizador dos interesses de seus múltiplos usuários.

\section{REFERÊNCIAS}

ABREU, V. Saneago diz que qualidade é boa. O Popular, Goiânia, ago. 2013. Seção Cidades. Disponível em: < http://www.opopular.com.br/editorias/cidade/saneago-diz-que-qualidade-\%C3\%A9-boa1.377406>. Acesso em: jun. 2017.

ANDRRÉASSIAN, V. Waters and forests: from historical controversy to scientific debate. Journal of Hydrology, 291, 1-27, 2004. Disponível em: <http://sci-hub.ac/10.1016/j.jhydrol.2003.12.015>. Acesso em: jun. 2017.

ANTUNES, Ó. E. D. Análise multicritério em SIG para determinação de um índice especializado de pressão antrópica litoral: Casos de Espinho, Caparica e Faro. 2012. Dissertação (Mestrado) - Faculdade de Ciências Sociais e Humanas, Universidade Nova de Lisboa, Lisboa, 2012.

BRASIL. Lei $\mathbf{n}^{\circ} \mathbf{1 2 . 6 5 1}$ (2012). Disponível em: < http:/www.planalto.gov.br/ccivil_03/_ato20112014/2012/lei/112651.htm>. Acesso em: jan. 2017.

BERTOLINI, D. Controle de erosão em estradas rurais. Campinas: Coordenadoria de Assistência Técnica Integral - CATI, 1993. 37 p. (Boletim Técnico, 207).

BURAK, S.; MARGAT, J. Water Management in the Mediterranean Region: Concepts and Policies. Water Resources Management, V(30), Issue 15, pp 5779-5797, 2016. doi: 10.1007/s11269-016-1389-4

COCCO, J.; RIBEIRO, H. V.; GALVANIN, E. A. S.; NASCIMENTO, D. L. Análise e Previsões das Ações Antrópicas para a Bacia do Rio do Sangue-Mato Grosso/Brasil. Revista de Estudos Sociais, v. 17, n. 34, p. 52-63, 2015.

CREPANI, E.; MEDEIROS, J. S.; PALMEIRA, A. F.; SILVA, E. F. Zoneamento Ecológico-Econômico. In: FLORENZANO, T. G. (Org). Geomorfologia: conceitos e tecnologias atuais. São Paulo: Oficina de Texto, 2008.

DPLP (Dicionário Priberam da Língua Portuguesa). Disponível em: $<$ http://www.priberam.pt/dlpo/Default.aspx>. Acesso em: jun. 2016.

GERGEL, S. E.; TURNER, M. G.; MILLER, J. R.; MELACK, J. M.; STANLEY, E. H. Landscape indicators of human impacts to riverine systems. Aquatic Sciences, v. 64, n. 2, p. 118-128, 2002.

GOUVEIA, R. G. L. de; GALVANIN, E. A. S.; NEVES, S. M. A. S. Aplicação do índice de transformação antrópica na análise multitemporal da bacia do córrego do bezerro vermelho em Tangará da Serra-MT. Revista Árvore, Viçosa - MG, v. 37, n. 6, p. 1045-1054, 2013.

HOULAHAN, J. E.; FINDLAY, C. S. Estimating the 'critical'distance at which adjacent land-use degrades wetland water and sediment quality. Landscape Ecology, v. 19, n. 6, p. 677-690, 2004.

IBGE (Instituto Brasileiro de Geografia e Estatística). Manual Técnico de Uso da Terra. $3^{\text {a }}$ edição. Rio de Janeiro: IBGE, 2013. $171 \mathrm{p}$.

JACOMIDE, P. K. T. A nova classificação brasileira de solos. Anais da Academia Pernambucana de Ciência Agronômica, v. (5-6), 161-179, 2008-2009. Disponível em: < https://ainfo.cnptia.embrapa.br/digital/bitstream/item/19350/1/Jacomine.pdf $>$. Acesso em: ago. 2016.

LANNA, A. E. Gestão dos recursos hídricos. In: TUCCI. C. E. M. (org.). Hidrologia: ciência e aplicação. Porto Alegre - RS: Ed. da Universidade Federal do Rio Grande do Sul - UFRS - ABRH, 1993.

LIMA, J. E. F. W. Situação e Perspectivas Sobre as Águas do Cerrado. Ciência e Cultura, v. (63), n. 3, 27-29, 2011. Disponível em: <http://cienciaecultura.bvs.br/pdf/cic/v63n3/a11v63n3.pdf >. Acesso em: nov. 2016.

LOURENÇO, R. W. SILVA, D. C. C.; MARTINS, A. C. G.; SALES, J. C. A.; ROVEDA, S. R. M. M.; ROVEDA, J. A. F. Use of fuzzy systems in the elaboration of an anthropic pressure indicator to evaluate the remaining forest fragments. Environmental Earth Sciences, v. 74, n. 3, p. 2481-2488, 2015.

MEDEIROS FILHO, C. F. de. Abastecimento de Água. Campina Grande: Universidade Federal de Campina Grande-UFCG, 2009. 
MENDONÇA, J. F. B. Solo: substrato da vida. 2. Ed. Brasília, DF: Embrapa Informação Tecnológica, 2010.

MORETO, L. Urban governance and multilateral aid organizations: The case of informal water supply systems. Rev Int Org, v. (2), 345-370, 2007. DOI 10.1007/s11558-006-9006-6.

NAJI, F.; LUSTIG, T. On-site water recycling - a total water cycle management approach. Desalination, 188 (1-3), 195-202, 2006.

NAYARA, J. Água do reservatório sob risco. O Popular, Goiânia, ago. 2013. Seção Cidades. Disponível em: $<\quad$ http://www.opopular.com.br/editorias/cidade/\%C3\%A1gua-do-reservat\%C3\%B3rio-sob-risco1.377405>. Acesso em: jun. 2017.

OLIVEIRA, B. S.; MATAVELI, G. A. V. Avaliação do desempenho dos classificadores Isoseg e Bhattacharya para o mapeamento de áreas de cana-de-açúcar no município de Barretos-SP. In: XVI SIMPÓSIO BRASILEIRO DE SENSORIAMENTO REMOTO (SBSR), 2013, Foz do Iguaçu. Anais eletrônicos... São José dos Campos: INPE, 2013. INPE. Artigos, p. 0089 - 0096. Disponível em: < http://www.dsr.inpe.br/sbsr2013/files/p0863.pdf>. Acesso em: ago. 2016.

OLIVEIRA, P. T. S.; WENDLAND, E.; NEARING, M. A.; SCOTT, R. L.; ROSOLEM, R.; Rocha, H. R. The water balance components of undisturbed tropical woodlands in the Brazilian cerrado. Hydrology and Earth System Sciences, v. (19), n. 1, 2899 - 2910, 2015. Disponível em: http:/www.hydrol-earth-systsci.net/19/2899/2015/hess-19-2899-2015.pdf. Acesso em: ago. 2016.

PÁDUA, G. O.; SOUZA, H. A. Reservatório da Barragem do Ribeirão João Leite em Goiás: Análise, Importância e Uso. In: V CONGRESSO BRASILEIRO DE GESTÃO AMBIENTAL, 2014, Belo Horizonte. Anais eletrônicos... Belo Horizonte: IBEAS, 2014. Disponível em: < http://www.ibeas.org.br/congresso/Trabalhos2014/VIII-003.pdf>. Acesso em: ago. 2016.

RABElO, C. G.; FERREIRA, M. E.; ARAÚJO, J. V. G.; STONE, L. F.; SILVA, S. C.; GOMES, M. P. Influência do uso do solo na qualidade da água no bioma Cerrado: um estudo comparativo entre bacias hidrográficas no Estado de Goiás, Brasil. Revista Ambiente e Água, v. 4, n. 2, p. 172-187, 2009.

RESENDE, P. Ribeirão João Leite tem 23 nascentes que já não podem ser recuperadas. G1- GO, Goiânia, fev. 2015. Seção Goiás. Disponível em: < http:/g1.globo.com/goias/noticia/2015/02/ribeirao-joao-leite-tem23-nascentes-que-ja-nao-podem-ser-recuperadas.html>. Acesso em: ago. 2016.

ROCHA, S. P.; CRUZ, C. B. M. Aplicação do ITA na análise espaço-temporal do entorno da BR-101 nos municípios de Angra dos Reis e Parati. In: XIV SIMPÓSIO BRASILEIRO DE SENSORIAMENTO REMOTO (SBSR), 2009, Natal. Anais eletrônicos... São José dos Campos: INPE, 2009. Artigos, p. $3087-$ 3094. Disponível em: < http://www.dsr.inpe.br/biblioteca/ >. Acesso em: ago. 2016

SALOMÃO, F. X. T. Controle e prevenção dos processos erosivos. In: GUERRA, T. A. J.; SILVA, A. S. \& BOTELHO, R. G. (Organizadores). Erosão e Conservação dos solos: conceitos, temas e aplicações. Rio de Janeiro: Bertrand Brasil, 1999.

SANEAGO. Relatório Anual da Qualidade da Água Distribuída. Secretaria das Cidades, 2008. Disponível em: < http://www.saneago.com.br/novasan/sudoa/arquivos/Goiania_JOAO\%20LEITE_08.pdf >. Acesso em: jun. 2016

SANTOS, A. M.; GOMIDE, M. L. C. A Ocupação no entorno das Terras Indígenas em Rondônia, Brasil. Boletim Goiano de Geografia, v. 35, n. 3, p. 417-436, 2015.

SANTOS, R. M.; KOIDE, S. Avaliação da Recarga de Águas Subterrâneas em Ambiente de Cerrado com Base em Modelagem Numérica do Fluxo em Meio Poroso Saturado. Revista Brasileira de Recursos Hídricos, v. (21), n. 2, 451-465, 2016. doi: http://dx.doi.org/10.21168/rbrh.v21n2.p451-465.

SOUSA, C. O. M.; FREITAS, S. R.; DIAS, A. A.; GODOY, A. B. P.; METZGER, J. P. O papel das estradas na conservação da vegetação nativa no Estado de São Paulo. In: XIV Simpósio Brasileiro de Sensoriamento Remoto (SBSR), 2009, Natal. Anais eletrônicos... São José dos Campos: INPE, 2009. Artigos, p. 30873094. Disponível em: < http://www.dsr.inpe.br/biblioteca/ >. Acesso em: ago. 2016.

SOUSA, S. B. Impactos da implantação da barragem no Ribeirão João Leite sobre a oferta de hortifruti na Grande Goiânia. Boletim Goiano de Geografia, v. 33, n. 2, p. 313-334, 2013.

SUHOGUSOFF, V. G.; PILIACKAS, J. M. Breve histórico da ação antrópica sobre os ecossistemas costeiros do Brasil, com ênfase nos manguezais do estado de São Paulo. Integração, Butantã, n. 51, p. 343-351, 2007. 
TUCCI, C. E. M. \& MENDES, C. A. Avaliação Ambiental Integrada de Bacia Hidrográfica. Brasília: MMA, 2006. Disponível em: < http://www.mma.gov.br/estruturas/sqa_pnla/_arquivos/sqa_3.pdf >. Acesso em: ago. 2016.

TUNDISI, J. G. Recursos hídricos no futuro: problemas e soluções. Estudos Avançados, v. (22), 7-16, 2008. doi: http://dx.doi.org/10.1590/S0103-40142008000200002

VIEIRA, J. M. P.; MORAIS, C. Planos de segurança em sistemas públicos de abastecimento de água para consumo humano. Instituto Regulador de Águas e Resíduos. Universidade do Minho. 2005. Disponível em: < https://repositorium.sdum.uminho.pt/bitstream/1822/4609/1/guia_7.pdf >. Acesso em: mai. 2016.

XIAOLI, C.; SHIMAOKA, T.; XIANYAN, C.; QIANG, G.; YOUCAI, Z. Characteristics and mobility of heavy metals in an MSW landfill: implications in risk assessment and reclamation. Journal Hazard Materials, V. (144), n. 1-2, 485-491, 2007.doi: https://doi.org/10.1016/j.jhazmat.2006.10.056 